\section{Biographical sketches}

Fred Nelson is Executive Director of Maliasili Initiatives which supports natural resource conservation, sustainable development, and social justice in Africa by working with leading local organizations to build their capacity to foster collaborative and innovative incentive-based solutions to conservation challenges. His research interests focus on community-based natural resource management, political economy and governance issues. Peter LiNDSEY works throughout Southern Africa on wildlife-based land uses, the bushmeat trade and predator conservation. He is Policy Initiative Coordinator for Panthera's Lion Program. Guy BALme is the Director of Panthera's Lion Program and also heads the organization's efforts to address poorly regulated trophy hunting and legal control of leopards in Africa. In addition, he is an Honorary Research Associate at the University of Cape Town.

\title{
ADDENDUM
}

\section{Trophy hunting and lion conservation: a question of governance?-ADDENDUM}

\author{
Fred Nelson, Peter Lindsey and Guy Balme
}

doi: 10.1017/So03060531200035X, Published by Cambridge University Press, 19 July 2013.

This article (Nelson et al., 2013) highlights several factors that undermine the conservation value of trophy hunting in Tanzania and that may result in negative impacts on wildlife populations (including lions) in some instances. Since the article was finalized, however, Tanzania has instigated three measures to improve the sustainability of lion hunting.

Firstly, a minimum 6-year age limit on lion trophies has been implemented (Tanzania Wildlife Division, 2012), forcing operators to be more selective when hunting lions. The age of lion trophies in Tanzania is assessed by an independent NGO and age restrictions are enforced via quota penalties for underage lion trophies (Tanzania Wildlife Division, 2012).

Secondly, lion quotas were cut from 520 in 2008-2009 to 315 in 2011-2012 (Tanzania Wildlife Division, 2012). There has been a drop in lion trophy off-takes, from 165 in 2008-2009 to 85 in 2011-2012 (Tanzania Wildlife Division, 2012), although research is required to determine the extent to which this decrease is because of the cut in the quota and age restrictions and/or a result of continued declines in lion populations. We recommend that formalized population monitoring is implemented to evaluate whether or not the reforms are translating into population increases.

Thirdly, changes were made in 2012 to the regulatory framework for community-based conservation, in the form of the Wildlife Management Area regulations. Although many of the challenges related to transferring management rights and economic benefits from wildlife on community lands still exist, the new regulations grant local communities that have established Wildlife Management Areas greater involvement in granting trophy hunting concessions, and provide greater clarity regarding the sharing of revenues generated by hunting. These much-needed improvements need to be developed further but have substantially improved some of the shortfalls that we describe in this article.

\section{References}

Nelson, F., Lindsey, P. and Balme, G. (2013) Trophy hunting and lion conservation: a question of governance? Oryx, 47, 501-509.

Tanzania Wildlife Division (2012) Comment on ESA Status Review of the African Lion. Unpublished Report. Wildlife Division, Government of Tanzania, Dar Es Salaam, Tanzania. 